\title{
More than sample providers: how genetic researchers in Pakistan mobilized a prenatal diagnostic service for thalassemia
}

\author{
Zainab Afshan Sheikh ${ }^{1,2}$ • Ayo Wahlberg ${ }^{3}$
}

Accepted: 31 October 2021 / Published online: 22 November 2021

(C) The Author(s) 2021

\begin{abstract}
While unequally resourced partners from the so-called global South are often considered 'mere sample providers' in larger international genomics collaborations, in this paper, we show how they strategically work to mobilize their role in a global system of tissue exchange to deliver services for local communities. We unpack how a prenatal diagnostic service for thalassemia in Pakistan emerged out of the maneuvering efforts of internationally connected Pakistani researchers. By tracing the distributed capacities that emerged and circulated as they set about improving medical genetics in Pakistan, we outline some key conditions that led to the establishment of the service: first, the scale of unmet needs that geneticists faced when collecting data as part of their research that made medical genomics a relevant field; secondly, joint efforts between researchers and physicians that were engaged with the challenge of decreasing disease prevalence through diagnostics and abortion; and finally, the ways in which international research collaborations helped generate resources to improve medical genetics in Pakistan. To understand how genetic research and medicine is currently being developed in Pakistan, we need to ethnographically re-center our analyses in ways that allow us to identify the resourceful ways in which researchers maneuvre to secure locally relevant outcomes.
\end{abstract}

Zainab Afshan Sheikh

zash@sund.ku.dk

Ayo Wahlberg

ayo.wahlberg@anthro.ku.dk

1 Centre for Advanced Studies in Biomedical Innovation Law, Faculty of Law, University of Copenhagen, Karen Blixens Plads 16, 2300 Copenhagen S, Denmark

2 Centre for Medical Science and Technology Studies, Section for Health Services Research, Department of Public Health, University of Copenhagen, Oester Farimagsgade 5B, 1014 Copenhagen, Denmark

3 Department of Anthropology, University of Copenhagen, Oester Farimagsgade 5E, 1353 Copenhagen, Denmark 
Keywords Pakistan - Genetic research $\cdot$ Reproductive genetics $\cdot$ Beta thalassemia International collaboration $\cdot$ Sample providers

\section{Introduction}

In 2008, in a crowded meeting room of a local hospital in Multan, Dr. Mahmoud, a Pakistani genetic researcher, delivered a passionate lecture about his research on the genetic mutations that can cause thalassemia to an audience of clinicians. Based on his collection of samples and family pedigrees among patients and their relatives in Faisalabad, Islamabad, and Karachi, he also described how prenatal diagnosis was possible. However, due to logistical challenges and the unavailability of an expert clinic that could extract the chorionic villus samples (CVS) from pregnant women, prenatal diagnosis had never been established as a well-functioning service. Sitting among the audience was a chief physician of the hospital, a radiologist named Dr. Ijaz. He immediately proposed that his team could perform the CVS procedure and handle all contact with patients and families in Multan and southern parts of Pakistan (recreated based on interviews and field notes, February 2017).

In this article, we show how a prenatal diagnostic service was made possible by researchers in Faisalabad who, in the context of the many connections to laboratories across the globe that they had, could easily be (and indeed were by some) characterized as mere 'sample providers'. As captured in the above event from 2008, the establishment of a prenatal diagnostic service for thalassemia in Pakistan involved a happenstance meeting between a researcher and a clinician: through a chain of events and strategic maneuverings, this meeting ultimately led to the establishing and maintenance of prenatal screening for thalassemia, free of costs for the hospital patients using it. While Dr. Mahmoud had been involved in international and national genetics research on thalassemia for some years, the hospital in Multan received hundreds of patients a year who were struggling with the condition on a daily basis.

Thalassemia affects the production of the hemoglobin molecule, which in turn affects its ability to optimally carry oxygen. When symptomatic, this can lead to serious health issues such as anemia, fatigue, and bone deformities. A particular classfication of thalassemia, beta-thalassemia major, is described as the most common genetic disorder in Pakistan. It is estimated to have nine million carriers, while 40,000 children are registered as transfusion dependent and 5,000-9,000 children are born annually with the condition (Ahmed et al. 2021; Ansari et al. 2018). During the last decade, prenatal diagnostic services for thalassemia alongside other congenital conditions have been on the rise within both the public and private sector in a number of major cities in Pakistan. However, recent developments notwithstanding, genetic services still remain limited or unavailable in most parts of the country, due to lacking regulation of medical genetics services and limited resources for developing clinical genomics expertise (Riaz 2019). Geneticists have highlighted how the accumulation 
of thalassemia and many other genetic mutations in Pakistan are rooted in cultural forms of kinship i.e., closed caste systems and intrafamily marriage practices which create and maintain biological specificities over generations (Fareed and Afzal 2017). For this reason, Pakistan has attracted global interest in research on congenital conditions, as they can reveal biochemical pathways that give insights to the pathophysiology of other conditions and basic human biological differences. A focus on translating research findings into public health outcomes in Pakistan has been lacking (Riaz et al 2019). The establishment of screening services for thalassemia is further challenged by the fact that the only effective 'cure' in case of a discovered mutation through prenatal screening is termination of pregnancy, from the point of view of doctors, geneticists, and families, due to the lack of health care facilities and a stable therapeutic transfusion system. Restrictive abortion law and practice in Pakistan also complicates prenatal screening given that, as Rayna Rapp has put it, "the possibility of late abortion shadows the experience of (...) and is the barely hidden interlocutor of all prenatal testing" (1999, p. 129). In Pakistan, termination of pregnancy can be performed to save a woman's life under the general criminal law principle of necessity. This means that termination of pregnancy is criminalized unless it is performed in 'good faith to save the women's life' or carried out in early stages of pregnancy (before 120 days) to provide 'necessary treatment' (Azmat et al. 2012). While there is no definition given as to what constitutes 'necessary treatment', in practice, many health care providers in Muslim countries have over time carried restrictive beliefs, generally refusing to carry out abortions when approached by women (Hessini 2007). Given these socio-economic, juridical, and cultural conditions, how then has it been possible for a prenatal diagnostic service to emerge and stabilize through international research in Pakistan?

In what follows, we show how the grounding of medical genetics in Pakistan emerged out of the maneuvering efforts of researchers facing unmet medical and social needs and challenges in their communities. Even though the target population for prenatal screening for thalassemia were not their own research participants, the screening service constituted a way for them to 'give back' to society. They teamed up with a hospital department that had clinical expertise to establish the screening service against a backdrop of no available treatment options, restrictive abortion laws, and numerous logistical challenges. Through international collaborations researchers mobilized financial resources and know-how: biological samples, family histories, and clinical tests from local families were a type of 'currency' for the researchers. Tracing the introduction of medical genetic services has allowed us to highlight the multifarious ways in which researchers in Pakistan are much more than 'mere sample providers' in larger international genomics collaborations. We argue that more empirical attention needs to be paid to the ways in which researchers in the so-called global South ${ }^{1}$ are invested in the building up and establishing of

\footnotetext{
1 When referring to researchers and studies from the global South, we do acknowledge that the term has a history of debates on what it is actually defining. The World Bank uses it to refer to low- and middle-income countries located in Asia, Africa, Latin America and the Caribbean which contrast to the high-income nations of the global North. For good reasons this simplification has been criticized for being descriptively inaccurate, homogenizing and geographically deterministic. In comparison with 'Third World' and 'Developing World', however, it has been considered to carry more weight in resisting hegemonic forces and describing a specific political space.
} 
research fields and relevant clinical applications on a daily basis, not as subordinates in global research assemblages, but rather as important contributors in the establishing and development of, in the present case, medical genetics in Pakistan.

\section{Methods}

This study is based on ethnographic fieldwork at a laboratory in Faisalabad which has formed international networks where tissue samples, family pedigrees, and clinical tests are collected from families living in local and rural areas of Punjab and Khyber Pakhtunkhwa and then circulated internationally to laboratories in Sweden, Denmark, Germany, the USA, Switzerland, France, and China in order to study inherited mutations and genetic components in over 70 different disease categories. The laboratory primarily collects data from families that have Mendelian or monogenic diseases in which single genes are involved (for example microcephaly and ataxia), but also from families with common disorders (for example stutter and schizophrenia) in order to find the autosomal recessive links. The empirical material for our analysis is based on field observations and interviews collected by the first author from 2015-2020. She went on two fieldtrips to Pakistan, for a total of five months. She interviewed research leaders from the Pakistani laboratory in Faisalabad and from its Danish collaborating laboratory in Copenhagen that has funded sample collections on multiple diseases and hosted $\mathrm{PhD}$ students from Pakistan since 2007. Two physicians working with prenatal diagnosis of thalassemia at the hospital clinic in Multan were also interviewed. She visited the homes of, and interviewed 36 families who participated in the genetic research, and six families who had used the prenatal diagnostic service. She also followed and interviewed 15 researchers, eight men and seven women, working for the laboratory in Faisalabad in their different tasks: in the field, collecting samples, pedigrees, and clinical information from two provinces of Pakistan, Punjab ,and Khyber Pakhtunkhwa; and in the laboratory, preparing the samples and other relevant information to be shipped to foreign collaborators and while doing karyotyping (a test that detects chomosomal abnormalities) for prenatal diagnosis. Most of the researchers were PhD students, while some were hired during their Master's degree studies. Zainab stayed at a dormitory located on the same campus as the laboratory, where many of the researchers also lived. During analysis, both authors read interview transcripts and field observations and met for a series of analysis meetings to discuss emerging themes, with a specific emphasis on the various forms of medical genetic work that informants were engaged in as researchers. Ayo Wahlberg has previously carried out ethnographic research on the development and routinization of assisted reproductive technologies in China, which provided a productive comparative backdrop for thinking about the introduction of medical genetic services in Pakistan.

The ethnographic fieldwork in Pakistan was based on a tradition of studying research that is Western-led while 'locally' implemented in resource-poor settings. Substantial contributions have been made to this field of study from the perspective of global bioethics, empirical ethics, postcolonial readings of data collection, and approaches that focus on the socialities of data collection in practice (Anderson 
2002; Biruk 2018; Geissler et al. 2008; Kingori 2013). These perspectives borrow and combine work from the disciplines of sociology, anthropology, philosophy, and science and technology studies (STS). Building on these studies, we draw different perspectives together in the following to argue for a re-centering of vantage point that allows ethnographers to identify the resourceful ways in which researchers maneuvre to secure locally relevant outcomes.

\section{Social studies of biomedical research in the global South}

In recent social studies of biomedical research in the global South, scholars have highlighted the inherently unequal relations that often characterize international research collaborations involving partners in the global North. Parker and Kingori (2016) have shown how researchers in low-income settings are often justifiably worried that they will be "relegated to the role of "a glorified field worker" and how they fear that "invitations to join collaborations are (...) primarily for access to samples (...) motivated by tokenistic reasons-such as to give the appearance to funders that researchers from a particular region were involved" (ibid., 4-5). Likewise, Geissler (2015) has argued that the influx of transnational biomedical research in Africa runs the risk of creating "an archipelago of well-protected islands of modern science and government, enclosures in which (...) laboratories and data-processing units are established in air-conditioned high-quality buildings or pre-equipped containers adjacent to crumbling health facilities; transnational scientists working in these sites train their (African and overseas) graduate students in leading European and American universities, rather than national universities" (ibid., 14). Similarly, Biruk (2018) has argued that even "though anthropologists and historians have aimed to foreground the maneuverings, knowledge practices, and experiences of a wide variety of middle men and invisible technicians, (...) intermediary local actors (...) have long been eclipsed in accounts of (post)colonial science that cast heroic scientists and Western experts as drivers of knowledge production" (ibid., 8; see also Kingori 2013; Molyneux et al. 2013).

Each of these studies has been important for highlighting the stratified condition of medical research on a global level. The use of words such as "middle men", "intermediary local actors", "sample providers", "data collectors", or "fieldworkers" firmly situates researchers in low-income settings in the link between distant (international) researchers/funders/policymakers and local communities in low-income countries (Petryna 2007; McKay 2017). However, empirical vantage points render such designations relative and fluid in important ways. An international science collaboration is one thing from the vantage point of a laboratory group based in Denmark that is interested in gaining access to biological samples from Pakistan and something quite different from the vantage point of a laboratory group in Pakistan that is continuously developing and establishing itself (much like laboratory groups are anywhere else in the world). As Anne Pollock has noted in her study of pharmaceutical knowledge-making in South Africa, "scholars in postcolonial anthropology have been increasingly interested in subverting traditional epistemiological hierarchies that see the Global South as the source of raw material and local knowledge, 
whereas the Global North is the source of transcendent knowledge" (Pollock 2014, 867-868, see also Raj 2007).

In this article, it is our intention to provide an ethnographic account of how international collaboration became relevant for a genetics laboratory in Pakistan rather than the other way around. In their ethnography of international clinical trial collaborations in Sri Lanka, Sariola and Simpson (2019) show how "the impetus for collaboration emerged from within the country rather than being driven solely by external interests" and how their clinician informants "were using collaboration and clinical trials to gain the desired outcome of future development" (ibid., 8-9; see also Kuo 2009). In similar ways, we explore how international collaborations were mobilized by a laboratory in Pakistan and merged with their efforts to develop relevant genetic research and ultimately to provide a new medical genetics service for a local hospital. As we will see, Danish partners, as one example of an international science collaboration studied here, explicitly referred to Pakistan as a place where you can pay collaborators to 'do collections'. Instead of defining 'equal partnerships', many collaborations today involve researchers of differing stature, funding status, and types of organization (Konrad, 2012). However, from the vantage point of the laboratory in Pakistan, the data collection among families that had a history of genetic disease were not only generative of salary, it also enhanced researchers' professional careers and resources that enabled a focus on social and medical needs in society.

Scientific research in the so-called resource-poor settings like those found in Pakistan is filled with myriad challenges related to limited funding and well-worn laboratory facilities (Geissler 2013). It is to such settings that 'capacity-building' initiatives, funded by various agencies from the global North, are brought to address diagnosed deficits in skills, technological know-how, and infrastructure. International policies have engaged capacity building as a means of "preventing exploitation of research subjects" (Levine 2001), and different forms of capacity building have been viewed as desirable in international collaborations by the researchers working within these collaborative projects (Okeke 2018; Parker and Kingori 2016; Beran et al. 2017; Wahlberg et al. 2013; Sleeboom-Faulkner et al. 2017; DouglasJones 2021). Yet capacity building as a concept has been criticized for presuming an expert North and a lay South where knowledge and skills are transferred unidirectionally from North to South (Montgomery et al. 2017; Sariola and Simpson 2019). What we studied is not earmarked capacity buidling or technology transfer from North to South, but rather different forms of distributed capacities: We give empirical attention to how capacities 'flow' or 'travel' (cf. Hoeyer et al. 2017; Andersen et al. 2020) and thereby come to be distributed and mobilized, by scientists and clinicians themselves, in Pakistan. Geissler and Tousignant (2016) have argued that capacity "arises from and acts upon dynamic relationships between materiality, time, skill, action, value and people_-sometimes in unpredictable ways, which is where ethnography can make its distinct contribution" (ibid, 351). We follow Douglas-Jones's and Shaffner's (2017) ethnographic approach to studying capacity building as a concept practice that attends "to how possibilities and potentials are invoked and mobilized in the pursuit of other ways of doing and being" in the "interplay of hope and insufficiency" (ibid, 6-7). Moreover, Kowal and Petersen (2015) 
have noted that "it is clear that science and technology impacts unequally on groups: different actors have different stakes in imagined or emerging biofutures" (ibid, 6). Based on the premise that capacity is not a trait embedded in specific entities, but rather a complex network activity enacted-or maneuvered-between humans, institutions, and technologies, we seek to understand the development of prenatal screening through the frictions between hope and insufficiency that researchers encounter when collecting biological samples and family histories that are ontologically multiple, and how this friction ultimately becomes productive (Mol et al. 2010; Latour 1999). As such, in this paper, we address how researchers cultivate and mobilize specific capacities relative to anticipated futures (LaHatte 2017).

\section{Making genomics relevant}

In an ideal setup, it should be like this: patients go to a clinician and the clinician refers them to a geneticist. I would prefer a setup like that. I am doing the job of a clinician, I am doing the job of a social worker, I am doing the job of a geneticist (Zaid, genetic researcher, March 2017).

In Pakistan, studying genetic disorders to understand inherited DNA mutations and their function is not a job limited to the laboratory. Zaid has been collecting blood samples and family pedigrees, as well as doing biopsies and clinical tests in various communities for six years. He articulates what it can be like to work with parts of research that are usually unrepresented in genetic research papers, but nevertheless take up significant time for Pakistani researchers: namely engaging families who have unmet medical and social needs. The status quo of prenatal disease diagnosis and treatment in Pakistan is located within a context of generally low and uncertain incomes, as well as under-resourced institutions of the state. Medical genetics has been a neglected field in many low-income countries, despite the fact that these countries provide biomaterial and trial populations for global medical research due to high accumulations of disease (Beighton et al. 2012; Christianson and Modell 2004; Alwan and Modell 2003; Nembaware and Mulder 2019). In the following, we show how the vision of medical genomics among genetic researchers in Pakistan figured side by side with multiple attempts at dealing with unmet needs in society. Zaid highlights the set of roles he is expected to perform and juggle between, which is no easy task. As there are no formal registers, the collection of health data and tissue samples had been handled through researchers' personal contacts and snowball sampling ever since a laboratory for genetic research was established in 1995 in Pakistan.

During the first years of the newly established laboratory, thalassemia was the core research subject. In 2005, several other gene discovery projects were incorporated into the work conducted by the laboratory, along with employing five $\mathrm{PhD}$ students, as international research laboratories started showing interest in Pakistani samples on different autosomal recessive conditions. Dr. Mahmoud, the Pakistani research leader, explained to Zainab that with time the disease was "well-described" and uninteresting for international collaborators. Yet, as he explained: "For local 
communities in Pakistan it is a major public health problem, as it has a carrier rate of approximately five percent of the population." Ever since establishing the research laboratory, it had become increasingly clear to the researchers that the localized circumstances that they worked in called for different forms of action. The seed for the prenatal genetic service was already planted before any international collaboration was established.

The recruitment of patients and families for research within the context of Pakistan was more contingent upon local society than the ideal setup that Zaid describes. Often, when researchers came to one family's home, word would spread about their visit and someone from a neighboring household would approach them and inform them of a child that was ill or disabled. The researchers would then evaluate if the condition was relevant for their study. In this sense, engagement practices with local populations are in situ and made possible through chance encounters and personal relations. Researchers most often sought out, engaged and visited affected families in the homes of local communities. They took samples from people in situations where they are unavoidably confronted with their life conditions. There is significant poverty-related vulnerability and illiteracy in Pakistan as many of the families participating in genetic research live with limited access to medical facilities and with generally low and uncertain incomes (see Sheikh and Jensen 2019).

One ambition of the research laboratory was to provide genetic counseling as a benefit-sharing mechanism to families enrolled in genetic research. One researcher, Farhad, explained: "I haven't met any person in Pakistan who has a lot of experience in this field. Perhaps there are some, but the thing is, we can only give counseling based on the information we have". Many researchers found it difficult to provide satisfactory genetic counseling to families. Even though thalassemia mainly presents as a single gene disorder inherited in autosomal recessive patterns, many of the conditions they study are complex disorders that are not characterized at a molecular level, and hence, impossible to screen for. Many cases of genetic counseling in the field were limited to researchers telling families to avoid intrafamily marriage. Taha explained: "Simply telling the families to avoid marriages with cousins is our only option, but it is not sufficient. With many of the diseases in Pakistan, the allele frequency is so high, that even if a couple is not consanguineous they are likely to be carriers of the same mutations". He acknowledged that they gave advice based on a deterministic way of seeing genetics, despite having the knowledge that this advice was not the most accurate or best. A senior scientist, Tanwir, who had been working for the laboratory and collecting samples for ten years and from at least 700 families in Punjab and Khyber Pakhtunkhwa, explained the importance of providing some kind of feedback due to the scale of prevalence in Pakistan: "There is a definition of when diseases are called rare, but in Pakistan the genetic disorders are not truly rare. We have so many of them, you go to areas and you find virtually every street with children affected with these "rare" [raises fingers to gesture air quotes] disorders. Treatment for the families is highly unlikely, but the level of hope for treatment is high [among families]. So, we have to do something. They need it". Complex, unclassified disorders are without treatment as their pathophysiology is unknown. Yet, as Tanwir notes, families have high hopes for some type of treatment. From his perspective, the sheer scale of incurable disease created an urge to act upon 
the situation. As noted, while thalassemia is "rare" in the European region and the region of the Americas, in Pakistan it is the most common inherited disorder (Colah et al. 2010). As for complex autosomal recessive conditions, many of them are also described as "common" by geneticists in localized contexts in Pakistan. Whether they are rare or common is, however, hard to tell: despite contemporary attempts to create a public database, there are no national-level studies or surveys on the prevalence of these diseases in the country, and patient registries on specific conditions exist in silos within hospitals.

Traditionally, research participation has been framed within the context of 'altruism', where researchers make clear to participants that there is no immediate benefit for participation in research (Appelbaum et al. 1987). However, many studies have shown how communities aspire to enroll in research projects in order to gain access to medical resources (Rajan 2007; Petryna 2009). Living in a setting where the health care system is unable to meet many of the needs of the most vulnerable families, the geneticists in Pakistan felt obligated to help the families in ways they could as they did not have a clinician in their team to provide medical support unrelated to the genetic research. Geissler (2013) has described how inequalities around health care facilities and lack of medicines remain "unknown knowns", never explicitly mentioned in the formal scientific work, while at the same time being something that local researchers unavoidably confront and hence try to navigate (ibid., 13). This is also the case for the Pakistani researchers. Another way that they tried to meet local needs during data collection for international projects was by providing selected families with wheelchairs, medicine, and transportation to hospitals. In these ways, capacities come to be distributed on the ground, through time-consuming efforts to help address unmet needs where possible, albeit invariably in limited ways.

In a different study of a trial community in Gambia, researchers' relations to research participants were guided by a concrete and relational form of ethics (Geissler et al. 2008). Similarly, in Pakistan, researchers' feedback to families during sampling trips was informal, "off-the-record" as they stated, and guided by the local engagement and initiative of the individual researcher carrying out the collections. As such, the researchers provide an important conduit for the families to gain access to medical help and knowledge about their condition. However, the researchers could not provide this ad hoc help for all 5,000 families they had engaged, which left researchers with feelings they themselves referred to as "guilt", "greed" and "selfishness", as they were in fact depending on families' samples to conduct international research. Kingori (2013) similarly found that data collectors working for medical research projects in western Kenya were affected by the living conditions of the people they met which "created tremendous stress, anxiety and feelings of guilt" (ibid., 366). In these ways, data collection creates moral friction. Annam, a geneticist, explained: "We need the samples, and I have myself been in a bad situation where I heard that many in the family had the same disease and I said: 'Wow, that's great,' because getting a large family with many cases is good for research". In this quote, we see how Annam was experiencing tension between finding families that would create research opportunities, while at the same time facing the desperation in which these families live. This is what she refered to as a 'bad' situation. 
In some cases, the genetic researchers in Pakistan would make false promises about a cure on the horizon to families that were desperate for relief, even though an actual cure or health care was not possible (Sheikh and Jensen 2019). Most of the researchers, however, talked about their vision of establishing a national screening center for genetic conditions as a moral responsibility they often felt when engaging local families. Their vision was articulated in spatio-temporal projections toward a "brighter future" for the country, where making the research relevant for the population was at the core of their motivation to work in genetic science. One researcher, Tanya, was especially dedicated to this aim, and explained that: "I am even willing to compromise my research career if I have to". In these ways, working toward meeting public health needs is not merely a 'side-effect' of researchers' work, as one might surmise from the vantage point of the international collaborator. Rather, the proposed national screening service is a vision that underpins their participation in international research projects.

\section{Establishing a prenatal diagnostic service}

It is not our duty. We are molecular geneticists and our job is to characterize these diseases. You see, this is a huge task. We don't find such huge numbers of disease anywhere else on this globe. Unfortunately, we have a very limited labor pool. Whatever screening and counseling we are doing, we are doing with our own funding. This is the job of the government but we are not getting even a single penny from the government. I think with the given resources we are doing fine. (Dr. Mahmoud, research leader, April 2017)

Dr. Mahmoud who is quoted above explained that his team of researchers are performing tasks related to prenatal screening that others ought to be doing. Despite describing it as a "non-duty", he was the primary driving force behind the screening service. There were also national desires to deal with thalassemia, for example, the Government of Punjab launched the "Punjab Thalassemia Prevention Program" in 2012 (functional in 2015) offering parts of the public in their province free screening and transfusion within the range of available resources. This program emerged in a different way that would need its own study. What it does show, however, is how a pressing need in society can be mobilized by many different types of actors at the same time. Due to the substantial research that Dr. Mahmoud had conducted on thalassemia, he designated the need to establish a mutation detection system for prenatal diagnostics, for women who were "at risk" of having a child with thalassemia a priority. As previously noted, in Pakistan, the condition is primarily inherited in an autosomal recessive pattern, which means that the parents of an individual with thalassemia each carry one copy of the mutated gene, but typically do not show signs and symptoms of the condition themselves. Through a prenatal test it is possible to diagnose if a fetus is affected by the blood disorder.

At the same time, however, the research laboratory did not possess the clinical expertise necessary to establish a screening service. It only had expertise in the karyotyping of tissue samples after they had been extracted. An essential part of 
making the vision of a screening service a reality, as we saw in the opening vignette of this article, was therefore the readiness of a hospital clinic in Multan to provide other essential components of the service. These included an invasive intervention to extract chorionic villus samples (CVS) - a procedure that carries risk for both woman and fetus, in which cells are taken from the placenta of the pregnant woman. This procedure is necessary to obtain fetal cells to do the diagnosis. Dr. Ijaz, chief physician at the hospital, explained that this service was initiated first and foremost because of the new opportunity to act upon what they experienced in their clinical practice as a huge disease burden of thalassemia through diagnostics. As he explained, the hospital clinic in Multan was eager to establish the service: "[Dr. Mahmoud] gave us a presentation. We didn't think long about it, I just asked him, 'Can we do it?' And then he said, 'Yes.' And that's how it started and I think we're doing a great job". This marked the beginning of joint efforts between doctors and researchers to make the prenatal screening a reality.

For the organization to work, the CVS has to move 150 miles from the hospital to the research laboratory in order for it to be tested for the five to six most common mutations in Pakistan through karyotyping. As there are no formal ways of doing this, samples are primarily sent between the two destinations by public bus, via an ordinary inter-city bus service for the general public. When the relevant tests are completed, an email with the results is sent by the laboratory worker to the physician in charge, leaving the communication and counseling of patients up to this physician and his team. The medical service was thus defined and handled purely by local Pakistani partners, based on a professionally founded and urgent need that they had identified in society. In these ways, the Pakistani researchers and doctors themselves decided which capacities to cultivate, relative to the anticipated future that they wanted to build. They found their own manageable solutions to do so. By 2020, approximately 1,300 first trimester prenatal diagnoses for thalassemia through analysis of chromosomal abnormalities had been conducted by researchers. Hassan, a researcher from Faisalabad, explained: "Through this service we provide more than just words. It's real help to the families, offered free of charge even though each test is usually approximately 30,000 PKR [approximately £150 GBP]". While the reasoning for establishing the prenatal service was tagged as 'real help', it was not without challenges and implications for families, researchers and clinicians, as we will now show.

As pioneers in the field of medical genetics, both researchers and doctors were occupied with introducing a geneticized disease model to communities (see also Shaw 2009). Even though genome editing technology has recently made treatment for thalassemia possible, there are no available options for gene therapy treatment for the general public (Biotechnology 2019). The only available 'treatment' in case of the detection of a mutation is termination of pregnancy. This is a highly contested practice in Pakistan. Until 1990, the Pakistan Penal Code criminalized abortion, unless it was performed in 'good faith to save the woman's life' (Jafri et al. 2012). Later on, an amendment widened legal permission to carry out abortion in the early stages of pregnancy, not only to save the life of the woman but also to provide 'necessary treatment' (Azmat et al. 2012). Pakistani law and medical practice is predominantly based on religious reasoning, with clear reference to Islamic scripture. 
For example, for 'necessary treatment', termination is allowed until 120 days of pregnancy as this marks the moment of ensoulment of the fetus - the moment when it is believed that personhood occurs and the fetus has rights. After 120 days of pregnancy, abortion is legal only to save a woman's life (Ilyas et al. 2009). Necessary treatment is not defined in the penal code, so it is up to the service providers and medical professionals to define this.

The sense of right and wrong, good and bad, in clinical practice in Pakistan is in many ways informed by cultural and religious normative standards rather than secular values that is the foundation of a euro-centric 'global' bioethics (Moazam 2006; See also Simpson 2016). During fieldwork, Zainab several times overheard that the deliberate termination of pregnancy at any stage of the pregnancy was considered wrong. There was a reluctance to abortion rooted in religious arguments of fate, ensoulment and divine will. However, people's religion can never be taken as a proxy for their behavior (Ahmed et al. 2006). It was not religious thoughts alone that formed the background for the choice of both families, researchers and clinicians dealing with thalassemia. Here, termination of pregnancy was considered "a different scenario" and thus necessary. In their engagements with families, the researchers and physicians were explicitly passionate about prenatal screening as a means of prevention, despite religious reasonings (se also Atkin et al 2008; Chattoo 2018). Traditionally, two main rationales are identified for the provision of prenatal testing. One is to expand women's reproductive choices and the other relates to reducing disease prevalence through discontinuation of pregnancy (Begović 2019). Diagnosing a thalassemia trait is different from actually having beta-thalassemia major. What is diagnosed is a homozygous mutation. Patients with a homozygous beta-thalassemia mutation usually have a severe transfusion-dependent beta-thalassemia major phenotype, but recent research has also identified a woman with an unexpected mild phenotype (Jiwu et al. 2021). Thus, identifying a mutation will always be about identifying a high risk of symptomatic thalassemia (see also Chattoo 2018). In our case, physicians would stress the high risk and therefore urge women to terminate their pregnancy if the mutation was detected. Zainab interviewed one physician, Dr. Bilal, saying that a women should discontinue pregnancy "for the sake of everyone, especially their unborn child". This directiveness was similar to that Tine Gammeltoft found in her ethnographic study of selective reproduction in Vietnam with one of the doctors she interviewed stating: "Letting such a child [with a severe prenatal diagnosis] live is a much bigger moral problem than aborting it. Such children will suffer and bring pain to their parents and to other people too" (Gammeltoft 2014, p. 112). In this way, a highly paternalistic approach to counseling families was defining for the reproductive choices that people could make in Pakistan as well, thereby promoting values that were commensurable with the practice of screening (cf. Hang 2018; Sariola and Simpson 2019).

By establishing the screening service it was already decided that thalassemia as a condition was severe enough for 'necessary' termination of pregnancy. By opting for screening, families were in many ways agreeing to this, albeit further studies of how families experience prenatal screening and diagnosis in Pakistan are certainly needed. Screening is most often initiated based on observed cases of thalassemia in other children or family members. Thus, most of the 
families opting for prenatal screening already had one child with the condition. As described by the doctors Zainab interviewed, the prospect of having another sick child was unbearable to most. People with moderate and severe thalassemia regularly need blood transfusions, along with iron chelation therapies that remove the excessive iron caused by the blood transfusion. Blood and marrow stem cell transplants are also possible, however access to this therapy is very limited for patients in Multan, and in Pakistan generally. These procedures are both costly and involve health risks. Dealing with these circumstances was an immense struggle for families. "Of course, I did what the doctors said," Saima, a woman who had opted for abortion after the screening result, explained. She continued: "We went through such a difficult time when we lost our first son when he was six years old. So, we have to listen to the doctor". Many of them wanted the screening so that they would not have to live through the despair of being unable to give their children needed care due to poverty. One father, Ahmed, who was afraid of losing his son, explained: "We just spent a whole month at the hospital. He's crying all the time. I'm living in great despair. I will not put this onto my next child". For Ahmed, finding a suitable blood donor, and paying hospital fees in order to take care of his child was a big worry, and termination of pregnancy was the only viable option.

Both researchers, families and clinicians followed the conviction, that the fetus was ensouled at 120 days after conception. Therefore they were trying to complete all procedures within this timeframe. However, in practice they were not always successful and the fetus could be up to 22 weeks at termination. The reason behind this lies partly in the organization: when international collaborations created new possibilities for the research laboratory to hire staff, they were also trained to conduct karyotyping of samples from patients undergoing the prenatal screening. The laboratory would not take money for the karyotyping, but instead the costs related to screening, like the ad hoc help provided during collections, would be adjusted against the resource inflow generated from research projects. In practice this meant that laboratory equipment was used for both clinical and research purposes interchangeably. As the laboratory devices were already there to perform research-related tasks, conducting the local prenatal screening was primarily a question of coordinating when to do the karyotyping in between other tasks as well as who should do it. This, however, was not without friction. The laboratory could be so busy at times doing research-related tasks that the clinic in Multan experienced delays in receiving screening results. If the laboratory had received more samples than they could process, or if other students were using the technological devices, the response time was delayed. In this way local aims at times became 'secondary', as the laboratory's obligations toward the international collaborators were prioritized over the prenatal service. This could disturb the work, as Bilal explained: "We are running against time, you know the [unborn] baby is getting bigger and bigger. The bigger the baby is, the more difficult it is to deal with". The strict 'deadline' of ensoulment (120 days of pregnancy) could potentially become problematic for the research laboratory. Conversely, prenatal screening tasks could also fill in inevitable waiting times related to research collaborations. Juggling with different temporal registers related to research, clinical and religious practice requires constant maneuvering and 
resource allocation. These examples depict how, in practice, researchers manage to utilize research facilities to local benefit in a constant maneuvering between legality, local understandings and professional tasks.

\section{Improving medical genetics in Pakistan}

The point of departure was of course that, because of the high rates of consanguinity in Pakistan, we would be able to find something that we normally can't find here [in Denmark]. It provides insight into the specific functioning of the genome and its variations (Prof. Jensen, research leader, January 2020).

As mentioned earlier, the international collaborators had no direct connection with the prenatal screening service established by the laboratory in Faisalabad which had already established a first international collaboration with another laboratory in Sweden in 2007 and later the same year with one in Denmark. This latter collaboration with the Danish laboratory was initiated by a Danish researcher who was interested in studying families with limb defects. The research leader of the Danish laboratory, Professor Jensen, who is quoted above, described his interest in Pakistani samples for basic scientific research. Based on a common interest in congenital limb defects, a Pakistani PhD student was able to visit the Danish laboratory. In 2010, Professor Jensen established a Basic Research Center, thereby broadening the scope of diseases the Danish research laboratory had funding to study, and thus expanding the collaboration with the Pakistani laboratory. Professor Jensen explained: "I sent him 100,000 DKK (£11,000 GPB) to make collections. You can get really far with that amount [of money] in Pakistan". Since then, the Pakistani laboratory has increased engagements in bilateral collaborations with ten other laboratories located in Europe, the United States of America and China. To date, the laboratory continues to establish new collaborations that go hand in hand with increasing collections of samples, family pedigrees and clinical tests on a variety of congenital conditions. The up-scaling of collections and collaborations have in turn created new possibilities for the research laboratory in Pakistan to hire staff and expand its work. One of these researchers, Taha, explained their relation to international collaborators in the following way:

It's very important for our research to have international collaborators. We don't have advanced sequencing facilities and advanced genetic analysis facilities available here in Pakistan, so for exome sequencing and next-generation sequencing it's very important for us. They have the facilities, but they don't have many samples or families to work with in the field of genetics. Pakistan, however, is a heaven for working in the field of human genetics.

As Taha explained, there is an exchange of technological facilities and genetic samples between the Pakistani laboratory and its international collaborators. As a part of the organization initiated by the Pakistani research leader, $\mathrm{PhD}$ students travel with the samples from Pakistan to collaborating laboratories where the facilities to conduct the research are present. A female PhD student, Laila, explained: "When we 
go, there also is the technology transfer with respect to knowledge. We learn how to sequence, we learn how to interpret data, so we're not only getting the support, we're also learning". Several of these student researchers were excited to collaborate with foreign laboratories, as it gave them the opportunity to travel and see the world, learn how to use technological resources and also to do research that only a few $\mathrm{PhD}$ students had the opportunity to do in Pakistan. Besides being an excellent source of learning and development, maintaining international collaborations was also equivalent to sustaining livelihoods. Taha, who had himself lost three children due to autosomal recessive diseases, explained that he was the main provider in his household. For him, traveling to Sweden and gaining new knowledge was a way to break the pattern of poverty and consanguinity which had been dominating his family for generations. One type of capacity building was being transformed into another. As has shown in another paper, "abroad" figures as a place of opportunity for the researchers participating in the international research undertaken by the laboratory (Sheikh and Hoeyer 2018, see also Crane 2010). The young researchers were, however, also very aware of the importance of their research endeavors remaining 'attractive' to foreign collaborative partners, due to unequal distributions of wealth, resources and health internationally. This could, in some interviews and situations, replace the excitement with descriptions of inferiority, especially in stories about getting much lower salaries during their stays in foreign laboratories than the European co-workers they were working beside. This reinforced the sense of unique possession related to sample collections among researchers. Given this relation, the collected biological samples, family pedigrees and clinical tests become a type of 'currency', an asset for the Pakistani researchers, exchanged for skills related to technology and funding which the researchers then adjusted for the purposes of helping the community satisfy unmet social and medical needs. The Pakistani research leader, dr. Mahmoud, for example, explained how his laboratory could cover prenatal diagnostic costs partly by "adjusting its [i.e., the genetic research projects'] budgets to these costs" not least in cases where the budgets for sample collections were primarily provided by international collaborators. The growing inflow of resources improved the contact to the local community and the screening service. We use 'currency' as a metaphor that 'commodifies' the genetic samples from participating families, to highlight the political economy surrounding samples from families with genetic conditions (Mitchell et al. 2006). As such, samples from families with many members affected by diseases of interest, become desirable. A desire which, as mentioned earlier, created distress and guilt among researchers-but also helped mobilize new ways of helping the local community. Many researchers agreed that it is important that the families are not treated as means to an end, even though in significant ways they are exactly that. In a different context, Susan Erikson (2019) has shown how "the profitization of suffering" is enabled in settings characterized by scarcity as it triggers opportunity. Samples are hence multiple: they are assets used strategically in exchanges with international collaborators, and at the same time they are a community that needs and wants help made to cohere through a range of tactics. Within their limited space for maneuvering, researchers engaged samples, family histories and clinical tests as a means of achieving desired ends. They used their involvement 
in international research collaborations as a way to enhance research and medical infrastructures in their country.

\section{Conclusion}

In this analysis, we have shown how genetic researchers in Pakistan are no 'mere sample providers'. Put in another way, they are only 'middlemen' if one's vantage point is that of researchers in, for instance, a Danish laboratory that send funds to a laboratory in Pakistan 'to make collections'. Hence, if we are to understand trajectories of innovation in medical genetics in Pakistan (and other countries of the global South), we will do well to empirically re-center our analyses in ways that allow us to identify the resourceful ways in which researchers maneuvre to secure locally relevant outcomes. As we have shown, researchers create opportunities, and distribute capacities, based on concrete socio-material practices: there is a constitutive entanglement between families living with unmet social and medical needs, the data collection practices of researchers, the hospital clinic and its physicians performing the CVS procedure, the technological laboratory equipment, the clinical/research tasks and the relations to international laboratories that shape the agency that researchers use to build important medical capacities. Through this study, it has been our aim to focus empirical attention toward the multiple and distributed capacities that researchers assemble through different types of maneuvering and the tacit work practices that shape their everyday working contexts.

This is not to overstate or romanticize the agency of actors in the global South who are clearly participating in international research on unequal terms. Our aim is not to deny power differences between actors and institutions, but rather to point to other things that are also taking place. Through their participation in international research, researchers in Pakistan are responding to an international agenda for basic scientific research. However, by paying closer attention to the local realities and health care infrastructures that they operate in on a daily basis, we found that they are equally responding strategically to their own agendas, and focusing on how to maximize the benefits of the collaborative relations for themselves and their local community. In this endeavor, samples, family histories, and clinical tests are mobilized by Pakistani researchers in particular exchanges to produce PhDs, fund researchers' salaries in Pakistan, and serve as access points to high-throughput technology and next-generation sequencing. The currencies generated through research are, thus, modified in order to help local communities in ways they find significant, even if limited. The prenatal services are not focused on the expansion of women's reproductive choices, but rather in a decidedly paternalistic manner on terminating pregnancies that are affected by thalassemia in order to relieve the (undetermined) burden of disease in Pakistan. Likewise, they do not contribute to the improvement of basic treatment for patients living with Thalassemia (see Chattoo 2018). In this way, they are working on the edge of abortion laws in Pakistan, in their efforts to control the spread of a disease through prevention. 
At the same time, the unease and discomfort that genetic researchers referred to when describing their interactions and reliance on families with numerous unmet social and unmet needs does not only help explain researchers' motivations to 'give something back'. This unease also highlights the stark inequalities that are likewise playing out within Pakistan as researchers engage with socioeconomically disadvantaged groups. Through their work, genetic researchers are directly implicated in the making of certain kinds of genetic populations which unavoidably also lead to possibilities and practices of discrimination and stigmatization (see Fullwiley 2007; Reardon 2017).

What we have focused on in this article is how genetic researchers in Pakistan innovate to make use of what there is in terms of resources and opportunities to help. If they were to work in different ways, not prioritizing and reinforcing a prevention discourse would require improved basic treatment in Pakistan. Much like anywhere else in the world, researchers in Pakistan are engaged in time-consuming efforts to generate funding, as well as to establish relations and what they perceive as benefits for the local communities they work with. In so many ways, given the resource-poor settings they are working in, making ends meet is all the more arduous and essential when compared to the daily work of researchers in the global north. As we have seen, researchers in Pakistan simultaneously navigate international research aims and local public health needs. These are not just 'unintended consequences' of international collaborations, rather they are very often the result of personal investments that drive researchers in their different forms of maneuvering (see also Bharadwaj 2016; Wahlberg 2018).

In order to understand and support the increasingly important role that in-country researchers play in introducing medical genetics into low-income settings, we have shown how analytically productive it can be to move beyond binary analyses of, on the one hand, research agendas for bioscientific knowledge and, on the other, agendas focusing on social and medical benefits for the people that provide samples for researchers. Focusing on the ways in which researchers strategically secure and mobilize resources and services between local realities and a global system of tissue exchange has brought us closer to understanding how genetic research and genetic medicine are currently being developed in Pakistan.

Acknowledgments We would like to thank Klaus Hoeyer, Anja M. B. Jensen, Ivana Bogicevic and Rachel Douglas-Jones who have generously commented on earlier versions of this paper.

Funding This project has received funding from the European Research Council (ERC) under the European Union's Horizon 2020 research and innovation programme (grant agreement number 682110). Funding was also provided by the Research Council of Norway (grant agreement number 294594) and H2020 European Research Council (Grant Number 682110).

\section{Declarations}

Conflict of interest The authors do not have any competing interests, intellectual or financial, in the research detailed in this paper.

Ethical approval The manuscript is comprised of original material that is not under review elsewhere, and the study on which the research is based has been subject to appropriate ethical review. 
Open Access This article is licensed under a Creative Commons Attribution 4.0 International License, which permits use, sharing, adaptation, distribution and reproduction in any medium or format, as long as you give appropriate credit to the original author(s) and the source, provide a link to the Creative Commons licence, and indicate if changes were made. The images or other third party material in this article are included in the article's Creative Commons licence, unless indicated otherwise in a credit line to the material. If material is not included in the article's Creative Commons licence and your intended use is not permitted by statutory regulation or exceeds the permitted use, you will need to obtain permission directly from the copyright holder. To view a copy of this licence, visit http://creativecommons.org/licen ses/by/4.0/.

\section{References}

Ahmed, S., H. Jafri, Y. Rashid, et al. 2021. Cascade screening for beta-thalassemia in Pakistan: Development, feasibility and acceptability of a decision support intervention for relatives. European Journal of Human Genetics 1: 1-8.

Ahmed, Shenaz, Josephine M. Green, and Jenny Hewison. 2006. Attitudes towards prenatal diagnosis and termination of pregnancy for thalassaemia in pregnant Pakistani women in the North of England. Prenatal Diagnosis 26 (3): 248-257.

Alwan, A., and B. Modell. 2003. Recommendations for introducing genetics services in developing countries. Nature Reviews Genetics 4 (1): 61-68.

Anderson, W. 2002. Introduction: Postcolonial Technoscience. Social Studies of Science 32 (5/6): 643-658.

Andersen, S.L., Ove Andersen, Janne Petersen, and Ayo Wahlberg. 2020. Traveling health-promoting infrastructures: A meta-ethnographic analysis. Health 24 (5): 606-622.

Ansari, S., and H., Sadia Parveen, Saima Siddiqui, Kousar Perveen, Ghazala Ahmed, Bushra Kaleem, Shariq Ahmed, Muhammad Zohaib, Tasneem Farzana, and Tahir Shamsi. 2018. Managing Thalassemia in the developing world: an evidence-based approach for prevention, transfusion independency, and curative treatment with hematopoietic stem cell transplantation. Blood Advances 2 (Suppl 1): 42-45.

Appelbaum, P.S., L.H. Roth, C.W. Lidz, P. Benson, and W. Winslade. 1987. False hopes and best data: Consent to research and the therapeutic misconception. Hastings Center Report 17 (2): 20-24.

Atkin, K., S. Ahmed, J. Green, and J. Hewison. 2008. Decision making and antenatal screening for sickle cell and thalassaemia disorders: To what extent do faith and religious identity mediate choice? Current Sociology 56 (1): 77-98.

Azmat, S.K., M. Bilgrami, B.T. Shaikh, G. Mustafa, and W. Hameed. 2012. Perceptions, interpretations and implications of abortions: A qualitative enquiry among the legal community of Pakistan. The European Journal of Contraception \& Reproductive Health Care 17 (2): 155-163.

Begović, D. 2019. Prenatal testing: Does reproductive autonomy succeed in dispelling eugenic concerns? Bioethics 33 (8): 958-964.

Beighton, P., K. Fieggen, A. Wonkam, R. Ramesar, and J. Greenberg. 2012. The University of Cape Town's contribution to medical genetics in Africa-From the past into the future. South African Medical Journal 102 (6): 446-448.

Beran, D., P. Byass, A. Gbakima, K. Kahn, O. Sankoh, S. Tollman, M. Witham, and J. Davies. 2017. Research capacity building-obligations for global health partners. The Lancet Global Health 5 (6): e567-e568.

Bharadwaj, A. 2016. Conceptions: Infertility and Procreative Technologies in India. Berghahn Books.

Biotechnology, Nature. 2019. First gene therapy for $\beta$-thalassemia approved. Nature Biotechnology 1102-1103.

Biruk, C. 2018. Cooking data: Culture and politics in an African research world. Durham: Duke University Press

Chattoo, S. 2018. Inherited blood disorders, genetic risk and global public health: Framing "birth defects" as preventable in India. Anthropology \& Medicine 25 (1): 30-49.

Christianson, A., and B. Modell. 2004. Medical genetics in developing countries. Annual Review of Genomics and Human Genetics 5: 219-265. 
Colah, R., Ajit Gorakshakar, and Anita Nadkarni. 2010. Global burden, distribution and prevention of $\beta$-thalassemias and hemoglobin E disorders. Expert Review of Hematology 3: 103-117.

Crane, J. 2010. Adverse events and placebo effects: African scientists, HIV, and ethics in the 'global health sciences.' Social Studies of Science 40 (6): 843-870.

Douglas-Jones, R. 2021. Committee as witness: Ethics review as a technology of collective attestation. The Cambridge Journal of Anthropology 39 (1): 55-71.

Douglas-Jones, R., and Justin Shaffner. 2017. Capacity building in ethnographic comparison. The Cambridge Journal of Anthropology 35 (1): 1.

Erikson, S. 2019. Faking global health. Critical Public Health 29 (4): 508-516.

Fareed, M., and Mohammad Afzal. 2017. Genetics of consanguinity and inbreeding in health and disease. Annals of Human Biology 44 (2): 99-107.

Fullwiley, D. 2007. The molecularization of race: Institutionalizing human difference in pharmacogenetics practice. Science as Culture 16 (1): 1-30.

Gammeltoft, T. 2014. Haunting images: A cultural account of selective reproduction in Vietnam: University of California Press.

Geissler, P.W. 2013. Public secrets in public health: Knowing not to know while making scientific knowledge. American Ethnologist 40 (1): 13-34.

Geissler, P.W. 2015. Para-states and medical science: Making African global health. Durham: Duke University Press.

Geissler, P.W., A. Kelly, B. Imoukhuede, and R. Pool. 2008. 'He is Now Like a Brother, I Can Even Give Him Some Blood'-Relational ethics and material exchanges in a malaria vaccine "Trial Community" in the Gambia. Social Science and Medicine 67 (5): 696-707.

Geissler, P.W., and Noémi. Tousignant. 2016. Capacity as history and horizon: Infrastructure, autonomy and future in African Health Science and Care. Canadian Journal of African Studies / Revue Canadienne Des Études Africaines 50 (3): 349-359.

Hang, T. M. 2018. Global debates, local dilemmas: Sex-selective abortion in contemporary Viet Nam. ANU Press.

Hessini, L. 2007. Abortion and Islam: Policies and practice in the Middle East and North Africa. Reproductive Health Matters 15 (29): 75-84.

Hoeyer, K., A. Tupasela, and M.B. Rasmussen. 2017. Ethics policies and ethics work in cross-national genetic research and data sharing: Flows, nonflows, and overflows. Science Technology \& Human Values 42 (3): 381-404.

Ilyas, M., M. Alam, H. Ahmad, and S. Ghafoor. 2009. Abortion and protection of the human fetus: Religious and legal problems in Pakistan. Human Reproduction \& Genetic Ethics 15 (2): 55-59.

Jafri, H., S. Ahmed, M. Ahmed, J. Hewison, Y. Raashid, and E. Sheridan. 2012. Islam and termination of pregnancy for genetic conditions in Pakistan: Implications for Pakistani health care providers. Prenatal Diagnosis 32 (12): 1218-1220.

Jiwu, L., Manna, S., Lai, M., Ying, Z., \& Yanhui, L. 2021. Hyperhaemolysis in a pregnant woman with a homozygous $\beta 0$-thalassemia mutation and two genetic modifiers. Molecular Genetics \& Genomic Medicine, e1696.

Kingori, P. 2013. Experiencing everyday ethics in context: Frontline data collectors perspectives and practices of bioethics. Social Science and Medicine 98: 361-370.

Kowal, E., and A. Petersen. 2015. Sociology of bio-knowledge at the limits of life. Journal of Sociology $51(1): 3-8$.

Konrad, M. 2012. Collaborators collaborating: Counterparts in anthropological knowledge and international research relations. Oxford: Berghahn Books.

Kuo, W.-H. 2009. The voice on the bridge: Taiwan's regulatory engagement with global pharmaceuticals. East Asian Science, Technology and Society: An International Journal 3 (1): 51-72.

LaHatte, K. 2017. Professionalizing persons and foretelling futures capacity building in post-earthquake Haiti. Cambridge Journal of Anthropology 35 (1): 17-30.

Latour, B. 1999. Pandora's hope: Essays on the reality of science studies. Cambridge: Harvard University Press.

Levine, R.J. 2001. Ethics for biomedical research involving humans: International codes. In International Encyclopedia of the Social \& Behavioral Sciences, ed. Neil J. Smelser and Paul B. Baltes, 47884792. Oxford: Pergamon.

McKay, R. 2017. Medicine in the meantime: The work of care in Mozambique. Durham: Duke University Press. 
Mitchell, R., C. Waldby, B.H. Smith, and E.R. Weintraub. 2006. Tissue economies: Blood, organs, and cell lines in late capitalism. Durham: Duke University Press.

Moazam, F. 2006. Bioethics and organ transplantation in a Muslim society: A study in culture, ethnography, and religion. Indiana: Indiana University Press.

Mol, A., Ingunn Moser, and Jeannette Pols. 2010. Care in practice: On tinkering in clinics, homes and farms. Care in Practice 8.

Molyneux, S., Dorcas Kamuya, Philister Adhiambo Madiega, Tracey Chantler, Vibian Angwenyi, and P. Wenzel Geissler. 2013. Field workers at the interface. Developing World Bioethics 13 (1): ii-iv.

Montgomery, C.M., Patricia Kingori, Salla Sariola, and Nora Engel. 2017. STS and global health. Science \& Technology Studies 30: 2-12.

Nembaware, V., African Genomic Medicine Training Initiative, and N. Mulder. 2019. The African genomic medicine training initiative (AGMT): Showcasing a community and framework driven genomic medicine training for nurses in Africa. Frontiers in Genetics 10 (1209).

Okeke, I.N. 2018. Partnerships for now? Temporality, capacities, and the durability of outcomes from global health "Partnerships." Medicine Anthropology Theory 5 (2): 16.

Parker, M., and P. Kingori. 2016. Good and bad research collaborations: Researchers' views on science and ethics in global health research." PLOS ONE 11(10)

Petryna, A. 2007. Clinical trials offshored: On private sector science and public health. BioSocieties 2 (1): 21-40.

Petryna, A. 2009. When experiments travel: Clinical trials and the global search for human subjects. Princeton and Oxford: Princeton University Press.

Pollock, A. 2014. Places of pharmaceutical knowledge-making: Global health, postcolonial science, and hope in South African drug discovery. Social Studies of Science 44 (6): 848-873.

Raj, K. 2007. Relocating modern science. Circulation and the construction of knowledge in South Asia and Europe, 1650-1900.

Rajan, K.S. 2007. Experimental values-Indian clinical trials and surplus health. New Left Review 45: 67-88.

Rapp, R. 1999. Testing women, testing the fetus: The social impact of amniocentesis in America. New York: Routledge.

Riaz, M., J. Tiller, M. Ajmal, et al. 2019. Implementation of public health genomics in Pakistan. European Journal of Human Genetics 27: 1485-1492.

Reardon, J. 2017. The postgenomic condition. Ilinois: University of Chicago Press.

Sariola, S., and B. Simpson. 2019. Research as Development: Biomedical Research, Ethics, and Collaboration in Sri Lanka. Cornell University Press.

Shaw, A. 2009. Negotiating risk. British Pakistani experiences of genetics. New York, Oxford: Berghahn Books.

Sheikh, Z., and K. Hoeyer. 2018. "That is why I have trust": unpacking what 'trust' means to participants in international genetic research in Pakistan and Denmark. Medicine Health Care and Philosophy 21 (2): 169-179.

Sheikh, Z., and A.M.B. Jensen. 2019. Channeling hope: An ethnographic study of how research encounters become meaningful for families suffering from genetic disease in Pakistan. Social Science \& Medicine 228C: 103-110.

Simpson, B. 2016. IVF in Sri Lanka: A concise history of regulatory impasse. Reproductive Biomedicine \& Society Online 2: 8-15.

Sleeboom-Faulkner, M., Haidan Chen, and Achim Rosemann. 2017. Regulatory Capacity Building and the Governance of Clinical Stem Cell Research in China. Science and Public Policy 45 (3): 416-427.

Wahlberg, A. 2018. Good quality: The routinization of sperm banking in China. Oakland, California: University of California Press.

Wahlberg, A., C. Rehmann-Sutter, M. Sleeboom-Faulkner, G. Lu, O. Doring, Y. Cong, A. Laska-Formejster, J. He, H. Chen, H. Gottweis, and N. Rose. 2013. From global bioethics to ethical governance of biomedical research collaborations. Social Science \& Medicine 98: 293-300.

Publisher's Note Springer Nature remains neutral with regard to jurisdictional claims in published maps and institutional affiliations. 
Zainab Afshan Sheikh is a postdoc at the Centre for Advanced Studies in Biomedical Innovation Law, Faculty of Law, University of Copenhagen and affiliated to the Centre for Medical Science and Technology Studies, Faculty of Health, University of Copenhagen. Her interests revolve around health-related topics that focus on research engagement.

Ayo Wahlberg is a professor at the Department of Anthropology, Faculty of Social Sciences, University of Copenhagen. His interests revolve around reproductive genetics, and he is the author of numerous articles and Good Quality - The Routinization of Sperm Banking in China (University of California Press, 2018). 